\title{
El universo de Maurice Sendak: una nueva manera de representar la infancia
}

\section{Maurice Sendak's narrative universe: a new way of representing childhood}

ROSA TABERNERO SALA

VIRGINIA CALVO VALIO

UNIVERSIDAD DE ZARAGOZA

Artículo recibido el / Article received: 10-02-2016

Artículo aceptado el / Article accepted: 01-08-2016

RESUMEN: El concepto de literatura infantil se ha ido definiendo a lo largo del tiempo a través de propuestas de autores que han marcado una forma de entender el discurso literario dirigido a la infancia. Maurice Sendak es, sin duda, uno de esos autores, de tal modo que se le atribuye una suerte de «reinvención» de la literatura infantil. Tras establecer las bases sobre las que se asienta esta afirmación, se analizan desde esta perspectiva varias obras del autor, insistiendo particularmente en la metáfora como estrategia discursiva. La presencia de metáforas relacionadas con el ámbito de la comida constituye un elemento recurrente en la obra de Sendak, a manera de «intertexto restringido», en un sentido muy amplio.

Palabras clave: discurso literario infantil, duplicidad del receptor, álbum, Sendak, metáfora.

ABSTRACT: The concept of Children's Literature has been defined over time through proposals from authors who have made a way of understanding the literary discourse to children. Certainly, Maurice Sendak is one of those authors so he is attributed to a sort of «reinvention» of Children's Literature. After establishing the basis on which this statement is based, we analyze -from this perspective- various works by the author, with particular emphasis on the metaphor as a discursive strategy. Thus the presence of related metaphors in the fields of food constitutes a recurring element in the work of Sendak, seen in a way as a «restricted intertextuality» in a very wide sense.

Keywords: children's literary discourse, recipient duplicity, picture book, Sendak, metaphor. 


\section{INTRODUCCIÓN}

Uno de los debates más recurrentes en lo que a la literatura infantil se refiere, es la definición de su especificidad como discurso literario (Tabernero, 2005). Aunque el debate, en algunos casos, no ha sido superado y, prueba de ello, son las ausencias de la materia como tal en el ámbito académico y, sobre todo, en el crítico (Tabernero, 2005: 21-56), comenzamos a vislumbrar la presencia de autores clásicos que, de algún modo, marcan distintas maneras de aproximarse al lector infantil y acepciones que incorporan en su definición el devenir histórico del concepto de infancia a través de propuestas que definen todo un género.

Tal es el caso de Maurice Sendak, uno de los autores que ejemplifican ese concepto de autor clásico y, por ende, canónico, cuya creación corresponde a uno de los hitos fundamentales en el devenir de la literatura infantil. Italo Calvino (1992:13-20) definía hace un tiempo en qué consistía un clásico a través de varias notas que contribuían a caracterizarlo. No siendo fieles a la literalidad, podríamos decir, siguiendo la exposición de Calvino, que los clásicos son aquellos que soportan y reclaman la relectura, enriquecen a quien los lee, se insertan en los pliegues de la memoria individual y colectiva, nunca terminan de decir lo que tienen que decir y contienen las huellas del pasado para transformarse en algo equivalente al universo. Construyen del mismo modo al lector en relación consigo mismo y con su propio entorno, y vencen el paso del tiempo convirtiéndose en ruido de fondo vinculado a la actualidad.

Hace cincuenta años Where the Wild Things Are (Donde viven los monstruos) (1963) fue publicado en Estados Unidos por Harper \& Row, y lo que ha ocurrido con este álbum durante este tiempo obedece a esas notas con las que Calvino definía el concepto de clásico. En todo caso, cuando alguien se aproxima a la obra de Maurice Sendak comprueba que Chicken Soup with Rice (A Book of Months), Alligators All Around (An Alphabet); One Was Johnny (A Counting Book), Pierre (A Cautionary Tale), In the Night Kitchen (La cocina de noche) (1972), Higglety Pigglety Pop! or There must be more to life (Dídola, pídola, pon) (1978), The Sign On Rosie's Door (El letrero secreto de Rosie) (1980) o Outside Over There (1982), entre otros títulos, obedecen a esa definición de clásico con la que hemos comenzado estas líneas. Y es que, en realidad, clásicas son las obras de Sendak porque clásico es el universo que en ellas se plasma.

Maurice Sendak (Brooklyn, 1928 - Connecticut, 2012) perteneció a una familia judía de origen polaco. Fue un escritor e ilustrador de literatura infantil que ofreció una visión de la infancia que se adentra en el mundo onírico y trata 
sobre lo prohibido, la libertad y la obediencia, entre otros temas. Su pasión por la ópera, el teatro, la escenografía y el cine se reflejó en la concepción de sus obras.

\section{SENDAK Y LAS CLAVES DEL DISCURSO LITERARIO INFANTIL}

El universo de Sendak y su condición de clásico se sustenta en dos ideas fundamentales de las que se desprende todo lo que se pueda explicar posteriormente. En primer lugar, Sendak respeta enormemente la capacidad del lector infantil y a él se dirige de tú a tú, sin ocultamientos. Sendak cree en la infancia y en su poder de interpretación y desde ahí escribe e ilustra, compone sus obras. Significativa es la aportación de Art Spielgeman, quien destaca esta perspectiva en el formato de novela gráfica dejando estas palabras en la boca de Sendak: «En réalité l'enfance est riche, esentielle, mystérieuse, profonde. J'ai un très vif souvenir de la mienne. Je savais des choses terribles. Mais il ne fallait pas les dire aux adultes. Ça leur aurait fait peur...» (Spielgeman, 2006: 85).

El propio Sendak en distintas ocasiones manifestó esa fe en la solvencia de la infancia. Así en la entrevista que concedió a Lorraine ${ }^{1}$ habla de esta concepción:

Hay toda una teoría relativa a la infancia de la cual todos parten y cuando se trata de un libro ilustrado tratan de descubrir si se han seguido las «reglas» acerca de lo que se supone es correcto y saludable para los niños. Esto entra en conflicto, todo el tiempo, con esas cosas que son misteriosas. Los niños no necesitan de un enfoque pedante de los libros. Los niños son mucho más universales en sus gustos y pueden tolerar ambigüedades, peculiaridades y cosas ilógicas. Llegan a su inconsciente y las enfrentan lo mejor que pueden. [...] La ansiedad proviene de los adultos que sienten que el libro debe acatar un conjunto ritual de ideas acerca de la infancia, y se sienten inquietos si este acatamiento no se cumple. Un conflicto muy importante se suscita porque el artista no tiene en cuenta reglas específicas. El artista tiene que ser un poquito desconcertante, un poquito salvaje y un poquito desordenado (Lorraine, 2012).

1. Citamos a través de la reproducción que Imaginaria (núm. 314, mayo 2012) realizó en homenaje a Maurice Sendak de una entrevista publicada hace más de 30 años en el primer número de la revista Parapara, ejemplar editado por el Banco del Libro (Sección Venezolana de IBBY), el Proyecto Interamericano de literatura infantil (PILI) y el Instituto Autónomo Biblioteca Nacional de Venezuela (Caracas, junio de 1980) http://www.imaginaria.com. ar/2012/05/maurice-sendak-1928-2012/. 
Un poco más delante, siguiendo con sus respuestas dentro de la misma entrevista, Sendak hace referencia a uno de los presupuestos de lo que debe partir la literatura infantil, la idea del adulto escondido que plantea Perry Nodelman (2008: 76-81) como una de las líneas que explican la esencia de la literatura infantil. Detrás de toda creación dirigida a los niños existe un adulto que revive o recupera un concepto de infancia que procede del recuerdo y, por otra parte, la dualidad en que se mueve el discurso literario infantil adquiere su máxima representación en la combinación de texto o imagen, de tal modo que es esta última la que proyecta una sombra mucho más compleja del sentido que la que marca aparentemente el propio texto.

El artista pone elementos en su obra que vienen de lo más profundo de sí mismo. Los toma de una vena peculiar de su infancia, siempre abierta y viva. Este es un don especial. Él comprende que los niños saben más de lo que la gente supone. Los niños están dispuestos a enfrentarse con temas dudosos que los adultos quisieran que no conocieran. [...] Todo lo que tratamos de hacer seriamente es hablarles acerca de la vida ¿Qué hay de malo en esto? Y, de todas maneras, ya saben de la vida (Lorraine, 2012).

Esa confianza en la competencia del lector infantil se agudiza cuando defiende que un buen libro para niños debe ser, ante todo, honesto, debe decir la verdad.

En el informe que elabora Marcela Carranza (2007a) se recogen afirmaciones del propio Sendak en este sentido. Así mismo, Mónica Klibanski² (2012) presenta un espléndido estudio de la obra de Sendak y se detiene en cómo concibe Sendak la infancia, lo cual redunda en esa idea de la confianza en la competencia del lector. Para Sendak los niños conviven con la angustia y los miedos y la mejor manera de dominarlos es la fantasía. Así le declaró a Stephen Colbert (2012): "Yo no escribo "para" chicos. Yo simplemente escribo, y son los demás los que dicen: "Esto es para chicos."».

Por otra parte, y aquí radica el segundo eje que justifica esa concepción de clásico, Sendak defendió en todo momento la concepción del álbum como arte. Así, autores como Salisbury y Styles (2012: 21) entienden que a Sendak se le debe la invención del álbum como género y la conversión de este último en arte (cf. asimismo Rauch, 2012: 9). Del mismo modo Sophie Van der Linden (2006: 17; 2013: 113) explica a Sendak como el comienzo del álbum moderno en su modalidad narrativa a través de Donde viven los monstruos.

2. Citamos desde la referencia de la autora a la obra de M. Sendak: Caldecott \& Co.: Notes on Books and Pictures. Harper \& Collins, 1988. 
Paradigmática a este respecto resulta la entrevista concedida a Lorraine de la que hemos entresacado anteriormente algunos fragmentos y sobre la que ahora mismo volvemos para explicar cómo entiende la ilustración y, por ende, el álbum o libro ilustrado, en su caso:

[La ilustración]Puede ser una mera decoración o una expansión del texto. Es la versión del texto hecha por el ilustrador, es su propia interpretación. Es la razón por la cual uno es socio activo en el libro y no un mero eco del autor. Ser ilustrador es ser un participante, es ser alguien que tiene la misma importancia, al expresarse, que el autor del libro, y, ocasionalmente, más importancia que éste, pero ciertamente nunca es ser el eco del escritor (Lorraine, 2012).

Él define su ilustración como interpretativa y desarrolla toda una teoría sobre cómo debe ser la relación entre texto e imagen:

No se debe hacer jamás la misma cosa, no debe jamás ilustrarse exactamente lo que está escrito. Debe dejarse espacio en el texto para que la ilustración cumpla su función. Luego, se puede regresar a las palabras y entonces dan lo mejor de sí y la imagen cobra toda su dimensión. [...] Un libro ilustrado debe tener, cuando está terminado, ese aspecto de inconsútil (Lorraine, 2012).

Poco más se puede decir de la teoría del álbum y de la recepción infantil. Teresa Durán (2010: 187), cuando comenta los «efectos y afectos derivados de la lectura visual del libro álbum», indica que este último es algo más que un libro, es la plasmación de una forma de comunicación, basada en una forma de representación, que provoca un nuevo «modo de leer». En el caso de Sendak, estimamos que ese modo de leer se origina en una nueva forma de crear un discurso, de representar un mundo. Solo desde esta perspectiva se puede entender la unanimidad de la crítica, tal como hemos señalado anteriormente en una breve muestra, en considerar a Sendak como el autor que fija en los años 60, años en los que coincidió con autores tan relevantes como Ungerer, Sasek o Leo Lionni, las claves de la propuesta discursiva que denominamos álbum ilustrado o libro-álbum.

\section{SENDAK Y SU UNIVERSO}

De lo expuesto se infiere que la singularidad de Sendak se centra, como señalan Ballanger y Beau (2006: 86-94) en la visión compleja de la infancia y en su manera de concebir la duplicidad del receptor como una de las características de la literatura infantil. Sendak reflejó la infancia en todas sus dimensio- 
nes con su «lado oscuro», con los efectos de la cólera, la sexualidad, los celos, la agresividad, el miedo, como señala Selma Lanes (cit. por Ballanger y Beau, 2006: 87). Marianne Berissi (2013: 10) menciona esa cara oscura de la infancia cuando se refiere a la utilización del color y la luz en este autor.

En principio, la propuesta de Sendak se incorporaría a una corriente que parte de obras que, de algún modo, se desvían del didactismo con el que nace la literatura infantil, nos referimos a libros como Der Struwwelpeter de H. Hoffmann, Max y Moritz. Una historia de chicos en siete travesuras de W. Busch, Pinocho de Carlo Collodi (cf. M. Carranza, 2007b, 2007c), El contador de historias de Saki o Historia de un niñito bueno. Historia de un niñito malo de Mark Twain. Ya no se trata de un infancia ejemplar y modélica, sino de niños con sus luces y sus sombras, niños que se explican a través de relaciones controvertidas de amor y odio respecto a los adultos, rasgos de rebeldía frente a la obediencia. En definitiva, personajes en los que el lector infantil proyecta sus sentimientos, sus sensaciones, sus quimeras, sus miedos, su rabia, sus relaciones de poder frente a los adultos, su necesidad de protección, su viaje hacia la madurez mientras el lector adulto entiende, desde el recuerdo, la incertidumbre de los protagonistas y su poder de creación.

Por otra parte, Sendak obedece a un pensamiento visual en la creación de todas sus historias. Él mismo se denominaba ilustrador interpretativo, tal como hemos definido anteriormente, y entendía que sus libros, aunque pudieran ser identificables, eran distintos porque la ilustración es secundaria en virtud del texto. Y este es un principio que no muchos ilustradores respetan en la construcción de los álbumes. Así la técnica que utiliza en cada obra es diferente, dependiendo de los textos o de las historias que construyen la base del discurso. Véase, si no, la diferencia entre las ilustraciones de Osito o ;Dídola, Pídola, Pon! y las de un libro como We are all in the Dumps with Jack and Guy: two Nursery Rhymes with Pictures, solo por poner un ejemplo.

El universo de Sendak es inabarcable, desde sus maestros (Blake, Caldecott, Chagall, Picasso, Matisse, entre otros) a su afición a la intertextualidad (Mickey Mouse, Oliver Hardy, King Kong, Ulises, etc.), pasando por un hondo conocimiento de la tradición popular y por la huella de la música y el teatro en todas sus composiciones. Sin embargo, lo que realmente individualiza la obra de Sendak es su gran empatía con el mundo del niño, en esa idea de que hay que aprender a convivir con los propios monstruos (cf. A. Garralón, 2000: 60-66), con una honestidad estética, que tal como menciona Yolanda Reyes (2012), provoca una reinvención de la literatura infantil y de los lectores.

En esta reinvención desempeña un papel fundamental la idea que desarrolla Nodelman de la dualidad esquizofrénica en la que se mueve la literatura 
infantil y, por ende, el lector que se infiere de ella puesto que, tal como expresaba Nodelman (2010: 31), «incluso los textos que apoyan más radicalmente el disfrute de la anarquía infantil están, sin embargo implicados en sistemas culturales adultos».

\section{CLAVES DISCURSIVAS EN LA OBRA DE SENDAK. LA METÁFORA COMO EJE CONSTRUCTOR DEL DISCURSO LITERARIO INFANTIL ILUSTRADO}

La obra de Sendak ha dejado impronta en los procedimientos de construcción del discurso literario infantil ilustrado. En este sentido, tres características fundamentales definen esta propuesta discursiva:

- La intertextualidad como fundamento de construcción (Tabernero, 2012; 2013). Los títulos de Sendak tienden a plantearse como una red de obras que llevan a otras obras, a otros discursos, característica destacable cuando, por una parte, se trata de un receptor en formación al que se le plantean desafíos con los que construir el sentido y, por otra parte, se cuenta con un receptor adulto que contempla cómo el discurso literario y artístico se define a través de la complejidad del diálogo de unas obras con otras. Ejemplo es, sin lugar a dudas, La cocina de noche.

- Como hemos comentado anteriormente, Sendak define la relación entre texto e imagen en el álbum a través de lo que él mismo denomina texto inconsútil, puesto que imagen y palabra llenan los vacíos que cada uno de los códigos genera. Los teóricos que han estudiado el álbum como género o discurso han recurrido a esta característica para concretar una poética del álbum. Cada una de las obras de Sendak es paradigmática en la construcción de un discurso en el que palabra e imagen conforman un discurso vertebrado, sin costuras.

- Esa complementariedad que hemos mencionado implica que el discurso debe basarse en la sugerencia, en la connotación, más que en la denotación, puesto que texto e imagen se interpretan en los respectivos huecos. En esta línea es destacable la maestría con la que Sendak utiliza los tropos, sobre todo la metáfora, con el ánimo de generar y rellenar esos vacíos a los que nos hemos referido.

Extendería los límites de este trabajo profundizar en cada uno de los tres aspectos señalados, aspectos que constituyen las claves fundamentales con las que aproximarse a una poética del álbum y del libro ilustrado en nuestros días. 
Nos vamos a centrar, por tanto, en uno de ellos, en el último, con el fin de reflexionar sobre la importancia del autor en el ámbito de la literatura infantil.

La metáfora es, sin lugar a dudas, una de las estrategias discursivas más utilizadas por Sendak, ya que le permite construir sentidos entre líneas. Paul Ricoeur (2001: 53) destaca cómo desde Aristóteles la metáfora esconde un sentido icónico, puesto que describe lo abstracto bajo los rasgos de lo concreto. Toda metáfora consiste para él en «hacer ver», en mostrar. «Las palabras pintan cuando significan cosas en acción.» La metáfora solo existe en el discurso, tal como señalaba Genette en su acepción de figura y basa su especificidad en la connotación (Ricoeur, 2001: 199). Así el Grupo $\mu$ (1987: 176) entiende que la metáfora no es una sustitución del sentido como la sinécdoque sino una modificación del contenido semántico de un término. Por otra parte, tal como establece Spang (1979: 221), «en la metáfora se sustituye el término propio por otro cuya significación está con él en una relación de analogía». Por esta razón, Lausberg (1975) trata la metáfora como un tropo «por salto», por no guardar una relación real. En todo caso, lo que siempre implica la metáfora, como tropo, es una interpretación subjetiva de la realidad.

Y esta idea nos remite a lo que el propio Sendak expresaba en la entrevista que concedió a Lorraine (2012) cuando comparaba la condensación de significados del álbum con las forma de significar de la poesía lírica.

Creemos que en la utilización de la metáfora radica una de las grandes aportaciones de Sendak a esa reinvención de la literatura infantil y del lector que mencionábamos más arriba, puesto que este procedimiento de construcción del discurso se fundamenta en la dualidad más absoluta en ese acto de empatía con la infancia que explica el imaginario infantil, incluidos sus orígenes en el cuento popular, propuesta que Sendak conoce e incorpora a todas sus obras de un modo u otro. Uno de los factores que mejor define la relación entre imagen y palabra que Sendak reclama para un buen libro ilustrado es la ambigüedad en la que se mueve el sentido cuando la metáfora como procedimiento se convierte en una de las estrategias discursivas. Ello implica la colaboración del lector, la inserción de su intertexto para generar sentidos $\mathrm{y}$, sobre todo, la presencia de la connotación en la expresión de las emociones cuando el lector, por trayectoria como ocurre en el caso de la infancia, está falto de palabras (cf. Cochet, 2006: 110).

Con el ánimo de ejemplificar lo que hemos expuesto, nos vamos a adentrar en el análisis de una de las metáforas más utilizadas por Sendak en sus obras, las correspondientes al campo semántico de la comida, de los alimentos y de sus posibles significaciones. De tal modo es recurrente la presencia de este tropo que pudiéramos entender que funciona como si se tratara de un «intertexto 
restringido», en palabras de Ricardou (1973), al que el autor acude en repetidas ocasiones.

Nikolajeva (2014: 338) hace referencia a la importancia del alimento en la literatura infantil en comparación a su presencia en la literatura para adultos, puesto que define la relación entre adultos y niños desde el amor o el odio.

Sendak utiliza la fuerza connotadora de este campo semántico para definir las relaciones entre adultos y niños de modo que lector infantil y el adulto asumen la carga emocional del alimento en todas sus perspectivas. La comida se instala en la ambivalencia más absoluta, de la misma manera que los personajes de Sendak y el universo que ellos pueblan. Por una parte, su presencia o su ausencia sugieren relaciones afectivas inherentes a la infancia-amor/odio, obediencia/desobediencia, docilidad/rebeldía, protección/abandono-, mientras que el hecho de comer está vinculado a lo instintivo y salvaje en su sentido figurado.

La comida, el alimento, representan en Sendak, a través de sus connotaciones, el vínculo emocional, la seguridad, el afecto, muy relacionado, sin duda, con su ascendencia judía, por una parte; mientras que, por otra, indican los miedos, las angustias ante lo incontrolable, los temores propios de la infancia, tan presentes en la tradición popular, tradición que conocía a la perfección (cf. asimismo Zipes, 2014). Recuérdese, si no, la importancia del alimento en relatos como Hansel y Gretel, solo por poner un ejemplo. El propio Sendak, proyectando su experiencia, contaba: «Los monstruos eran mis tíos y tías que venían los domingos a comer nuestra comida [...] Los tíos nos podían comer si les entraba el hambre» (Garralón, 2000).

En la primera infancia, además, confluyen en el acto de comer tanto el medio más inmediato de conocimiento como de crecimiento, la comida ofrece un elemento narrativo de especial importancia. Lo impone su imperiosa necesidad; sin embargo, lo que le otorga la trascendencia es el cariño de la mamá que ha dedicado tiempo y atención a preparar una sopa que llenará de calor al niño que acaba de volver de su aventura, tal como señala Squilloni (2013: 11) en un espléndido artículo.

La metáfora, por tanto, con su naturaleza discursiva y connotativa, resume a la perfección el universo de Sendak, la dualidad tanto en su propuesta como en el lector al que se dirige. Un recorrido por la obra de Sendak nos dará cuenta de la capacidad del autor de condensar emociones y sugerencias, de hacer ver o mostrar lo abstracto a través de lo concreto. En definitiva, se trata de la metáfora como procedimiento de construcción de sentidos, en particular nos centramos en la metáfora sobre la comida, uno de los elementos que mejor resume la dualidad del universo de Sendak, de la infancia que refleja el autor, 
además de constituirse en uno de los rasgos que caracterizan la concepción artística del álbum o de libro ilustrado en la dinámica de colaboración entre imagen y palabra en la construcción de sentidos.

Pocos elementos de mayor fuerza narrativa como el final de Donde viven los monstruos, ${ }^{3}$ tal como refería más arriba Arianna Squilloni.

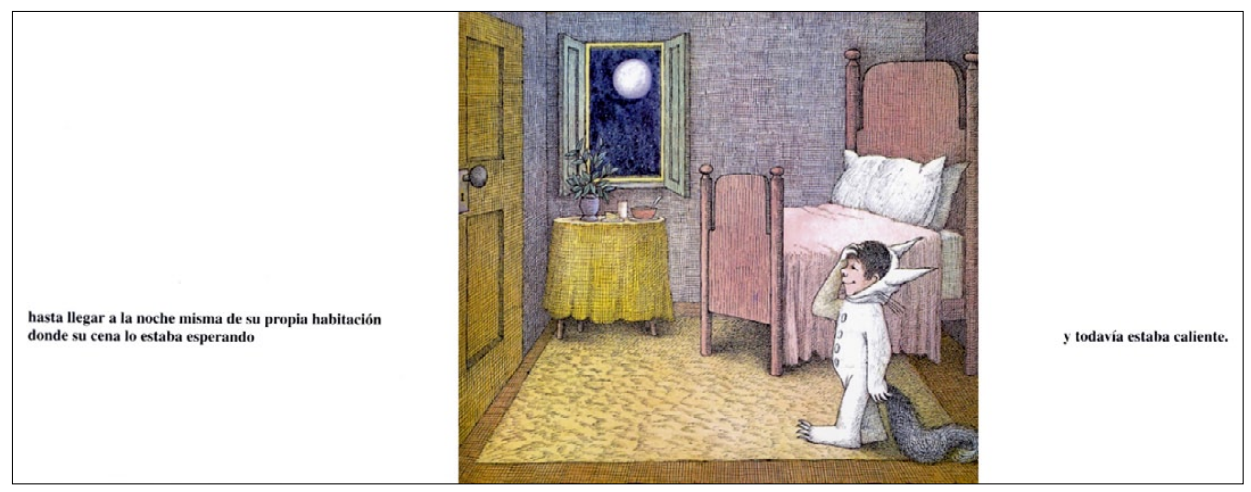

Max termina aquí su aventura y vuelve al lugar en el que «alguien le quisiera más que a nadie».

La comida, en esa dualidad en la que hemos insistido, es el vínculo del afecto, del hogar, de la seguridad, y guarda connotaciones de exigencia de sumisión por parte del adulto.

Una vez más, la ambivalencia del comer que se desprende también de la imagen, el lado oscuro de la infancia en esa persecución de Max, esos «niños malos» de los que hemos hablado anteriormente, junto a los que vuelven al lugar en el que su madre, el afecto, le está esperando. Pero no es su madre, sino la comida con todas sus connotaciones, esta vez del lado de la palabra:

Entonces desde el otro lado del mundo le envolvió un olor de rica comida y ya no quiso ser el rey del lugar donde viven los monstruos.

3. Citamos la edición española: Donde viven los monstruos. Madrid: Santillana. 2009. 


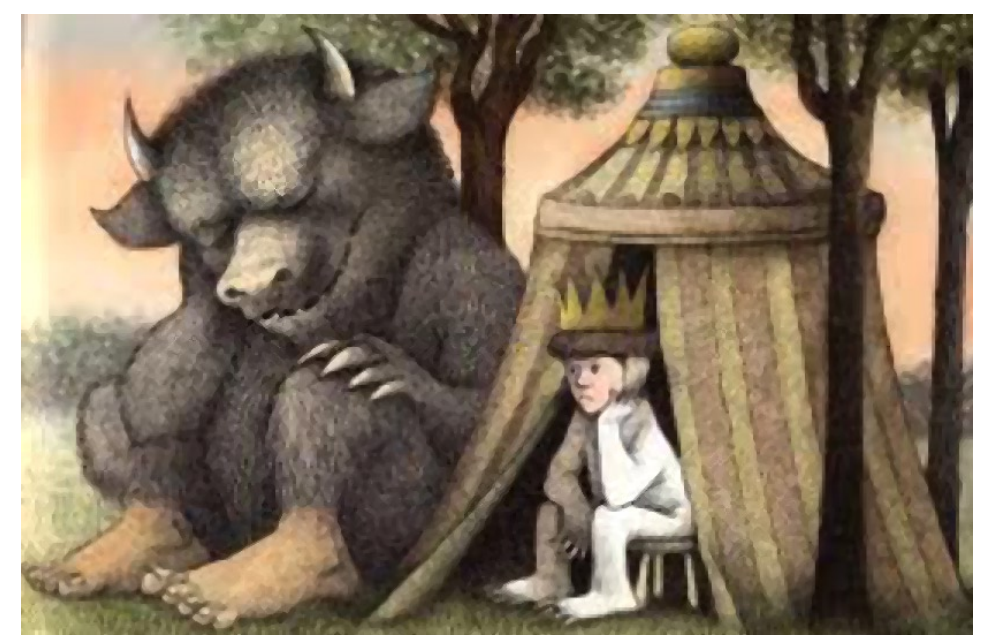

Como se podrá observar, la comida solo es mencionada por el texto y la imagen se centra en la melancolía con la que Max se expresa.

Y los monstruos vuelven a insistir en esa ambivalencia: «pero los monstruos gritaron: "iPor favor no te vayas -te comeremos-, te queremos tanto!”». Sin duda, reconocemos aquí los ecos de los cuentos maravillosos de los que nacen los monstruos que devoran carne humana.

La elipsis de la figura de la madre resulta muy sugerente. La comida, el alimento, es la metáfora de las emociones encontradas, de los afectos contrapuestos, de las relaciones filiales que se entienden desde la paradoja. ¿Será un reflejo de la experiencia vital del propio autor?

Podemos asimismo fijar nuestra atención en los libritos de la minibiblioteca de Maurice Sendak. Tanto Chicken Soup with Rice (A Book of Months), Alligators All Around (An Alphabet); One Was Johnny (A Counting Book), Pierre (A Cautionary Tale) confieren una presencia fundamental a la comida como algo inherente a la infancia desde la expresión de los afectos, la alegría y el juego, como es el caso de Chicken Soup with Rice, hasta la cólera, la agresividad que muestra Johnny con la amenaza de devorar a todos los que han invadido su hogar como no hayan desaparecido cuando llegue a casa. Del mismo modo, Pierre utiliza esta metáfora en su sentido dual como expresión de amor y odio. La madre lleva la comida y el máximo desprecio de Pierre es derramarlo encima de su cabeza. A Pierre todo le da igual en un acto de rebeldía. 


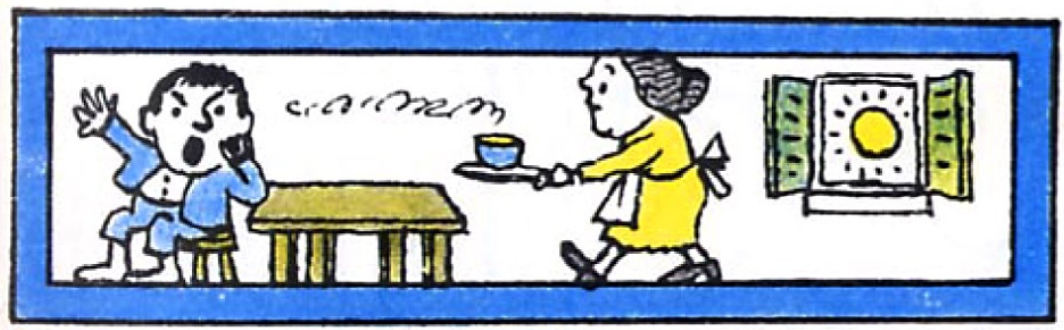

Al final, incluso le da igual que un león se lo coma. La imagen en ningún caso muestra cómo el león devora a Pierre. Solo vemos como lectores la aproximación -amable, por cierto- y la satisfacción del animal después. Otra vez un «monstruo» que devora y destruye, y un protagonista que desafía la autoridad.

Sin duda, uno de los mejores ejemplos de nuestra tesis es La cocina de noche (In the night Kitchen), obra, por otra parte, muy censurada, entre otras razones, por la desnudez del protagonista. En esta obra Miguel aterriza en sus sueños en la masa que había en la cocina y allí tres pasteleros lo batirán para hacer un pastel mientras el protagonista escapa en una avioneta de masa de pan. Desde allí les llevará la leche:
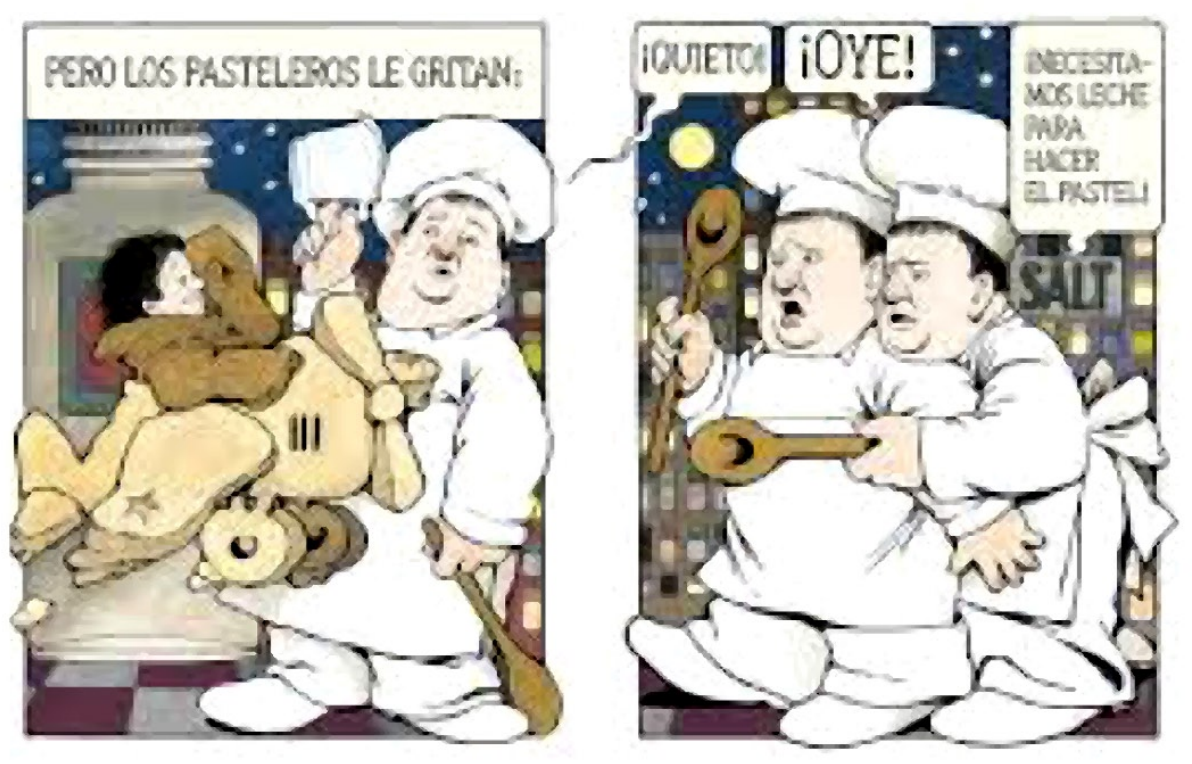
La simbiosis que se produce entre Miguel y los ingredientes del pastel connotan, por una parte, la necesidad de protección de la infancia, los requerimientos de lugares seguros y, por otra, la imagen de la aventura que supone el desapego. No olvidemos que Miguel escucha un ruido en la noche de su habitación y antes de aterrizar en la masa que le aguarda en la cocina dice: «Papá, Mamá».

Del mismo modo, Dídola Pídola Pon! o La vida debe ofrecer algo más. (Higglety Pigglety Pop! or There must be more to life), Bumble-Ardy (2002) el alimento define a los personajes centrales en su relación con el entorno. Otra de las obras en las que la metáfora del alimento como constructor de sentidos en la línea de una alegoría es, por ejemplo, We Are all in the Dumps (1993).

Cuando Sendak no escribe sino que ilustra textos de otros autores, la comida está presente tanto en su ambientación como en la expresión de los afectos. Tal es el caso de Osito (1997) y La visita de Osito de Minarik (2002). Estas obras son presididas por la delicadeza tanto del texto como de la ilustración. Los detalles con los que Sendak obsequia al lector contribuyen a definir un ambiente de afecto, hospitalario, en el entorno de Osito. La comida es, por una parte, una celebración de amistad, de comunión con la colectividad presidida por el amor incondicional. No se trata del acto instintivo de comer sino del acto social, de componente emocional, sofisticado, en todo caso, por el aderezo de manteles, ornamentos en la mesa y cuencos cuidadosamente dibujados a través de la técnica del punteado en plumilla tan característica de algunas de las composiciones de Sendak. Por otra parte, hay que reparar en que sobre el texto de diálogo creado por Minarik, Sendak construye un universo acogedor para el personaje principal a través de detalles domésticos entre los que destaca la indumentaria de la madre que utiliza en las ocasiones en que aparece con Osito un delantal muy propio de los contextos vinculados a la cocina. Así pues, el campo semántico del alimento acoge de una forma $u$ otra al protagonista para acunarlo en un entorno seguro repleto de afecto. Una vez más la metáfora del alimento «rellena» los vacíos que deja el texto para dotar al discurso de una trascendencia desconocida por el código verbal. 

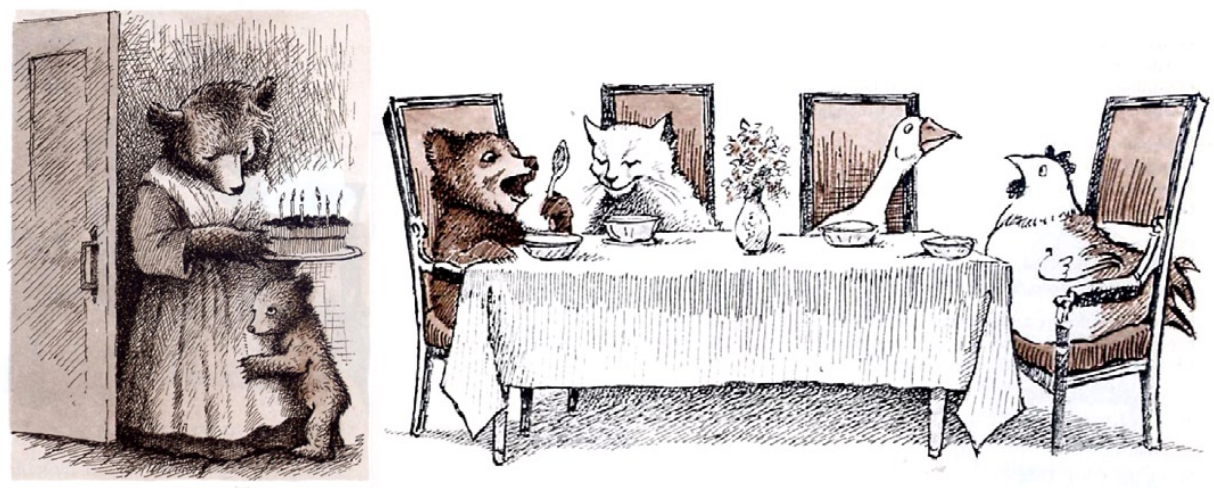

Así mismo, explícitamente el despliegue colorista de El Sr. Conejo y el regalo perfecto de Ch. Zolotow (2011) convierte la metáfora de la comida en el eje de la obra de tal modo que el universo, y con él el símbolo del amor más generoso, se concreta en una cesta de frutas. En esta obra, del mismo modo que en las anteriormente mencionadas, la comida adquiere un componente sensual y estético, puesto que son los colores los que guían a la niña en la búsqueda del regalo. El Sr. Conejo actuará de consejero y de la sugerencia de los objetos pasará a los alimentos, aunando en ellos tanto la presencia estética, la belleza, como la connotación de afecto, de cuidado, sugerida por la composición de las frutas elegidas en una cesta con el ánimo de eliminar de este modo los aspectos más primarios de la comida. Una nueva connotación, la de la belleza en las composiciones de las imágenes impresionistas en las que predominan las sensaciones, sorprende al lector en ese regalo que satisface tanto el cuerpo como el espíritu.

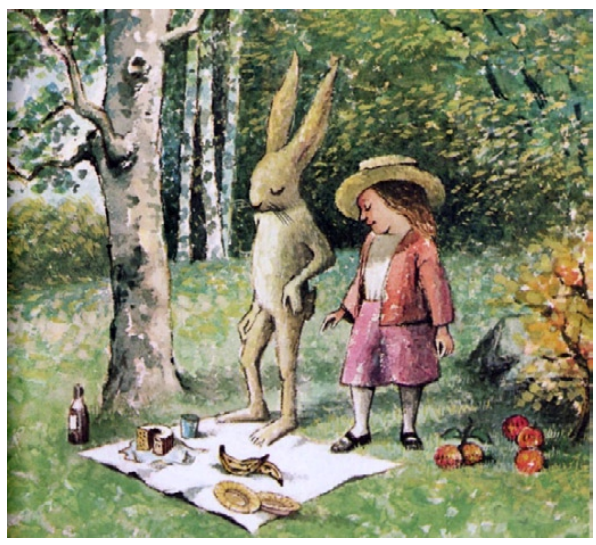




\section{PARA TERMINAR}

Valga este breve análisis de algunas obras de Sendak para entender su obra desde la maestría en la utilización de la metáfora como instrumento de connotaciones creador de sentidos nuevos a través tanto de la palabra como de la imagen. Desde el poder de concreción de la metáfora que se centra en el ámbito del alimento, Sendak definió la dualidad de la infancia, con sus lados claros y oscuros, con sus contradicciones emocionales, con el amor y el odio como sentimientos que conviven en el imaginario infantil y que tienen como punto de partida su propia experiencia. Narrativamente la metáfora resulta un recurso totalizador que sugiere lo máximo con lo mínimo y, a través del doble lenguaje de imagen y palabra, crea sentidos nuevos en los que se implica al lector en el espacio compartido del libro. En esto, como en otros muchos aspectos, Sendak fue un maestro e instauró un antes y un después tanto en la definición de la dualidad del receptor en el discurso literario infantil como, en lo que concierne, al álbum, como elemento necesario en la cultura infantil de nuestros tiempos.

\section{REFERENCIAS BIBLIOGRÁFICAS}

Ballanger, F.; N. Beau (2006): «L'œuvre de Maurice Sendak», La revue des livres pour enfants, 232: 86-94.

BERISSI, M. (2013): «Cómo se acerca el color a los niños», Fuera [de] margen, 13: 10 .

Calvino, I. (1992): Por qué leer a los clásicos, Barcelona, Tusquest.

Carranza, M. (2007 a): «Informe sobre Maurice Sendak», Imaginaria, 222. $<$ http://imaginaria.com.ar/22/2/sendak.htm>, (15-04-2014).

- $(2007 b)$ : «Tres clásicos entre la obediencia y la desobediencia (primera parte)», Imaginaria, 209. <http://www.imaginaria.com.ar/20/9/entre-laobediencia-y-la-desobediencia.htm>, (18-07-2014).

- (2007c): «Tres clásicos entre la obediencia y la desobediencia (Segunda Parte)», Imaginaria, 210. <http://www.imaginaria.com.ar/20/9/entre-laobediencia-y-la-desobediencia.htm>, (18-07-2014).

Cоснет, M. (2006): «Entrer dans l'univers de Sendak», La revue des livres pour enfants, 232: 108-117.

ColberT, S. (2012): Entrevista a Maurice Sendak (25/01/2012), recuperado de <http://www.refinery29.com/2015/06/88976/maurice-sendak-stephencolbert-interview $>$, (18-07-2014). 
Durán, T. (2010): «Efectos y afectos derivados de la lectura visual del libroálbum», en Colomer, T.; B. Kümmerling-Meibauwer; C. Silva-Díaz (coords.) (2010): Cruce de miradas: nuevas aproximaciones al libroálbum, Barcelona, Banco del Libro/Gretel. 186-203.

Garralón, A. (2000): "Una conversación informal con Maurice Sendak», Educación y Biblioteca, 113: 60-66.

Grupo M (1987): Retórica general (traducción de Réthorique générale, París, Editions du Seuil), Barcelona, Paidós.

IrIBARREN, E. (2000): «Un encuentro con Maurice Sendak», Enlaces con la crítica, 1: 2-6, Caracas, Banco del Libro-CONAC.

KLibanski, M. (2012): «Maurice Sendak y las profundidades de la infancia». $<$ http://www.educ.ar/sitios/educar/blogs/ver?referente=familias\&id=1063 21\&cat=ed_blogs_cat_familia>, (15-04-2014).

LAUSBERG, K. (1975): Elementos de retórica literaria, Madrid, Gredos.

LORRAINe, W. (2012): «El significado de la ilustración en los libros para niños. Entrevista con Maurice Sendak», Imaginaria, 314. <http://www.imaginaria.com.ar/2012/05/maurice-sendak-1928-2012/>, (01-08-2016).

Minarik, E. H. (1997): Osito (trad., M. Puncel), ilustraciones M. Sendak, Madrid, Alfaguara.

- (2002): La visita de Osito (trad., R. Benavides), ilustraciones M. Sendak, Madrid, Alfaguara.

Nikolajeva, M. (2010): «El poder y la subjetividad en el libro-álbum», en Colomer, T.; B. Kümmerling-Meibauwer; C. Silva-Díaz (coords.) (2010): Cruce de miradas: nuevas aproximaciones al libro-álbum. Barcelona, Banco del Libro/Gretel. 34-44.

- (2014): Retórica del personaje en la literatura para niños, México, Fondo de Cultura Económica.

Nodelman, P. (2008): The Hidden Adult, Baltimore, Johns Hopkins University Press (2010): «Las narrativas de los libros-álbum y el proyecto de la literatura infantil», en Colomer, T.; B. KüMmerling-MeIBAUWER; C. Silva-DíAz (coords.) (2010): Cruce de miradas: Nuevas aproximaciones al libro-álbum. Barcelona, Banco del Libro/Gretel, 18-32.

RAUCH, A. (2012): «Trace per una storia dell'albo», Hamelin, Ad occhi aperti. Leggere l'albo illustrato, Roma, Donzelli Editore, 3-19.

REYES, Y. (2012): «Onde vivem os monstros. Bons livros para crianças nem sempre boas», Emilia. <http://www.revistaemilia.com.br/mostra. php?id=190>, (15-04-2014).

RicARdou, J. (1973): Le Nouveau roman, París, Seuil. 
Ricoeur, P. (2001): La metáfora viva (traducción de La métaphore vive. París: Editions du Seuil. 1975), Madrid, Ediciones Cristiandad/Ediciones Trotta.

Salisbury, M.; STyles, M. (2012): El arte de ilustrar libros infantiles (traducción de Children's Picturebooks. Londres, Laurence King Publishing, 2012), Barcelona, Blume.

SEndaK, M. (1960): The Sign On Rosie's Door, Nueva York, Harper Collins Publishers.

- (1977): Donde viven los monstruos (Where the Wild Things Are) (trad., A. Gervás), Madrid, Alfaguara.

- (1978): ¡Dídola Pídola Pon! o La vida debe ofrecer algo más (Higglety Pigglety Pop! or There must be more to life), Madrid, Alfaguara.

- (1980): Outside over There, Londres, Randon House.

- (1991): Chicken Soup with Rice (A Book of Months), Alligators all around (An Alphabet); One Was Johnny (A Counting Book), Pierre (A Cautionary Tale), Nueva York, Harper Trophy.

- (1993): We Are All in the Dumps with Jack and Guy: Two Nursery Rhymes with Pictures, First Edition.

- (2002): Bumble-Ardy, Londres, Harper Collins.

- (2014): La cocina de noche (In the Night Kitchen) (trad., M. Azaola), Pontevedra, Kalandraka.

Sotelo, R. (2007): «Maurice, Max y los monstruos homenajeados», Imaginaria, 222. <http://www.imaginaria.com.ar/22/2/galeria.htm>, (15-042014).

SPANG, K. (1979): Fundamentos de retórica, Pamplona, Eunsa.

SpiegelmanN, A. (2006): «In the dumps», La revue des livres pour enfants, 232: 84 (reproducción de In bon baisers de New York, París, Flammarion, 2004).

SQuilloni, A. (2013): «A comer», Peonza, 105: 5-13.

TABERNERo, R. (2005): Nuevas y viejas formas de contar. El discurso narrativo infantil en los umbrales del siglo XXI, Zaragoza, Prensas Universitarias.

- (2012): «La hipertextualidad como fundamento de construcción en la literatura iluminada: la formación del lector en el libro-álbum y en el libro ilustrado» en Mendoza, A. (coord.) (2012): Leer hipertextos. Del marco hipertextual al lector literario, Barcelona, Octaedro, 121-134.

- (2013): «Libros que llevan a otros libros: la literatura "iluminada" en las bibliotecas escolares», Ensino Em Re-Vista, v. 20, 2: 315-340.

TuRIN, J. (2008): Ces livres qui font grandir les enfants, París, Didier Jeunesse. 
VAN DER Linden, S. (2006): Lire l'album, Le Puy-en-Vela, L'atelier du poisson soluble.

- (2010) : «Rêver est-il jouer? De la chambre à l'imaginaire, aller et retour», Hors cadre [s], 6: 12-15.

- (2013): Album $[\mathrm{s}]$, Éditions de Facto.

ZIPES, J. (2014): El irresistible cuento de hadas. Historia cultural y social de un género, México, Fondo de Cultura Económica.

Zolotow, Cн. (2011): El Sr. Conejo y el regalo perfecto. (Mr. Rabbit and the Lovely Present) (trad., M. Salas), Barcelona, Corimbo. 